\title{
High Resolution Distribution Dataset of Double-Season Paddy Rice in China
}

\author{
Baihong Pan ${ }^{1}$, Yi Zheng ${ }^{1}$, Ruoque Shen ${ }^{1}{ }^{\mathbb{D}}$, Tao Ye $^{2}$, Wenzhi Zhao ${ }^{2} \mathbb{D}$, Jie Dong ${ }^{3}$, Hanqing Ma ${ }^{4}$ \\ and Wenping Yuan 1,*
}

1 Southern Marine Science and Engineering Guangdong Laboratory, School of Atmospheric Sciences, Sun Yat-sen University, Zhuhai 519082, China; panbh3@mail2.sysu.edu.cn (B.P.); zhengy263@mail2.sysu.edu.cn (Y.Z.); shenrq3@mail2.sysu.edu.cn (R.S.)

2 Faculty of Geographical Science, Beijing Normal University, Beijing 100875, China; yetao@bnu.edu.cn (T.Y.); wenzhi.zhao@bnu.edu.cn (W.Z.)

3 College of Geomatics and Municipal Engineering, Zhejiang University of Water Resources and Electric Power, Hangzhou 310018, China; 201531480022@mail.bnu.edu.cn

4 Northwest Institute of Eco-Environment and Resources, Chinese Academy of Sciences,

Lanzhou 519082, China; mahq@llas.ac.cn

* Correspondence: yuanwp3@mail.sysu.edu.cn

Citation: Pan, B.; Zheng, Y.; Shen, R.; Ye, T.; Zhao, W.; Dong, J.; Ma, H.;

Yuan, W. High Resolution

Distribution Dataset of

Double-Season Paddy Rice in China.

Remote Sens. 2021, 13, 4609. https://

doi.org/10.3390/rs13224609

Academic Editors: Bin Chen,

Yufang Jin and Le Yu

Received: 15 October 2021

Accepted: 10 November 2021

Published: 16 November 2021

Publisher's Note: MDPI stays neutral with regard to jurisdictional claims in published maps and institutional affiliations.

Copyright: (c) 2021 by the authors. Licensee MDPI, Basel, Switzerland. This article is an open access article distributed under the terms and conditions of the Creative Commons Attribution (CC BY) license (https:// creativecommons.org/licenses/by/ $4.0 /)$.
Abstract: Although China is the largest producer of rice, accounting for about $25 \%$ of global production, there are no high-resolution maps of paddy rice covering the entire country. Using time-weighted dynamic time warping (TWDTW), this study developed a pixel- and phenology-based method to identify planting areas of double-season paddy rice in China, by comparing temporal variations of synthetic aperture radar (SAR) signals of unknown pixels to those of known double-season paddy rice fields. We conducted a comprehensive evaluation of the method's performance at pixel and regional scales. Based on 145,210 field surveyed samples from 2018 to 2020, the producer's and user's accuracy are $88.49 \%$ and $87.02 \%$, respectively. Compared to county-level statistical data from 2016 to 2019 , the relative mean absolute errors are $34.11 \%$. This study produced distribution maps of double-season rice at $10 \mathrm{~m}$ spatial resolution from 2016 to 2020 over nine provinces in South China, which account for more than $99 \%$ of the planting areas of double-season paddy rice of China. The maps are expected to contribute to timely monitoring and evaluating rice growth and yield.

Keywords: early rice; late rice; double-season rice; time-weighted dynamic time warping; synthetic aperture radar; planting area; remote sensing

\section{Introduction}

Paddy rice occupies more than $9 \%$ of the global cropland area [1] and is a staple food resource for more than half of the world population [2], and, therefore, plays an important role in supporting food security [3-6]. Paddy rice is an important water consumer and greenhouse gas emitter. The global average water consumption of paddy rice is $1325 \mathrm{~m}^{3}$ ton $^{-1}$, and the global water requirement of rice production is estimated to be 784 billion $\mathrm{m}^{3} \mathrm{yr}^{-1}$ [7]. In China, irrigating paddy rice needs 1.61 and 2.88 times more water than wheat and maize, respectively [8]. Paddy rice fields are also important sources of greenhouse gasses (i.e., methane, nitrous oxide) due to long-term flooding conditions [9]. Global estimates showed that paddy rice emits about 36 million tons of $\mathrm{CH}_{4}$ and contributes $2.5 \%\left(-0.1 \mathrm{~W} \cdot \mathrm{m}^{-2}\right)$ to radiative forcing [10]. Therefore, the accurate identification of paddy rice is quite important for monitoring food security, evaluating water resources, and accounting for greenhouse gas emissions.

Satellite-based methods are widely used to identify planting areas of paddy rice across regional and national scales as they provide spatially and temporally continuous observations [11-18]. Numerous efforts have been made to distinguish paddy rice from other crop types using optical and synthetic aperture radar (SAR) datasets separately or 
together $[19,20]$. Initially, traditional supervised and unsupervised methods were widely used for the classification of paddy rice [21,22]. More recently, machine learning methods such as random forest, support vector machine, and deep learning have been increasingly used for identifying paddy rice [23-28]. Thorp, et al. [29] used deep neural network methods with SAR and optical data from Sentinel 1 and 2 to produce multitemporal maps of paddy rice production stages across West Java, Indonesia. Based on the random forest algorithm and Sentinel data, Fiorillo, et al. [30] mapped lowland rice crop areas in the Sédhiou region (Senegal) from 2017 to 2019. However, the accuracy of these methods strongly depends on the number of training samples [31], which are difficult to obtain and update on a large scale [32].

An alternative method for mapping paddy rice takes advantage of its unique phenological characteristics [33]. The most important feature differentiating paddy rice from other crops is the flooding during the growing season [34]. Previous studies developed an automated mapping algorithm by using satellite-based water and vegetation indexes to detect the phase of flooding and open-canopy of paddy rice [11,12]. This phenology feature has been used for mapping paddy rice in Southern China and Southeast Asia using MODIS data. However, the planting areas of paddy rice are usually distributed in humid regions with frequent cloud cover, which largely limits the availability of optical data [35-37]. MODIS data can provide more cloud-free images because of high temporal resolution, but can't capture the heterogeneity of small and fragmented farmlands. In contrast, high spatial resolution optical remote sensing datasets have low temporal resolution, and are therefore severely impacted by the presence of clouds for mapping paddy rice in humid areas $[36,37]$.

In contrast to optical remote sensing, SAR signals penetrate through clouds and, therefore, can be used under various weather conditions [38-40]. SAR systems are active sensors that emit a radar pulse and record the land surface signal return at the satellite. Water bodies are specular reflectors of the radar pulse, resulting in a minimal or no signal to be returned to the satellite [41,42]. During the flooding and rice transplanting periods, the canopy of rice seedlings is not closed and, therefore, surface waters dominate the satellite response with low values. Guo, et al. [43] added four SAR features to capture the flooding signals, reducing the limitations of lacking optical data during the flooding and transplanting periods. There have been several studies that have used SAR data to map paddy rice, such as in Shanghai of China [44] and Camargue of France [45]. The SAR-based methods were shown to be an effective method for identifying rice areas across different latitudes and planting systems $[46,47]$.

About $25 \%$ of global rice production takes place in China. The most common cropping type is double-season rice (early rice and late season rice) and its planting area is concentrated in nine southern provinces. In spite of its importance, there is no high spatial resolution double-season paddy map (i.e., 10 or $30 \mathrm{~m}$ ) covering the entire region. The objectives of this study are to fill this gap by: (1) developing a pixel- and phenologybased algorithm to classify double-season rice using SAR images; and (2) mapping the distribution map of double-season paddy rice over nine provinces in South China.

\section{Materials and Methods}

\subsection{Study Area}

In China, there are two rice cropping systems: one-season rice and double-season rice. This study aims to identify the planting areas of double-season rice over nine provinces (Table 1; Figure 1), which account for more than $99 \%$ of the planting areas of doubleseason rice in China according to the statistical data from 2016 to 2019. Double-season rice includes two types of cropping patterns: early rice-late rice (Type I) and other crops-late rice (Type II). Type I accounts for $91.45 \%$ of areas of double-season rice averaged over all provinces (Table 1). 
Table 1. Statistical area of early rice and late rice averaged from 2016 to 2019.

\begin{tabular}{ccc}
\hline Province & Early Rice $\mathbf{( \mathbf { 1 0 } ^ { \mathbf { 3 } } \mathbf { h a } )}$ & Late Rice $\mathbf{( \mathbf { 1 0 } ^ { \mathbf { 3 } } \mathbf { h a } )}$ \\
\hline Anhui & 195.03 & 197.15 \\
Fujian & 115.12 & 248.59 \\
Guangdong & 845.05 & 953.09 \\
Guangxi & 799.32 & 839.78 \\
Hainan & 124.03 & 119.92 \\
Hubei & 176.45 & 193.80 \\
Hunan & 1317.08 & 1370.96 \\
Jiangxi & 1219.70 & 1320.21 \\
Zhejiang & 92.22 & 97.33 \\
Sum & 4883.99 & 5340.83 \\
\hline
\end{tabular}

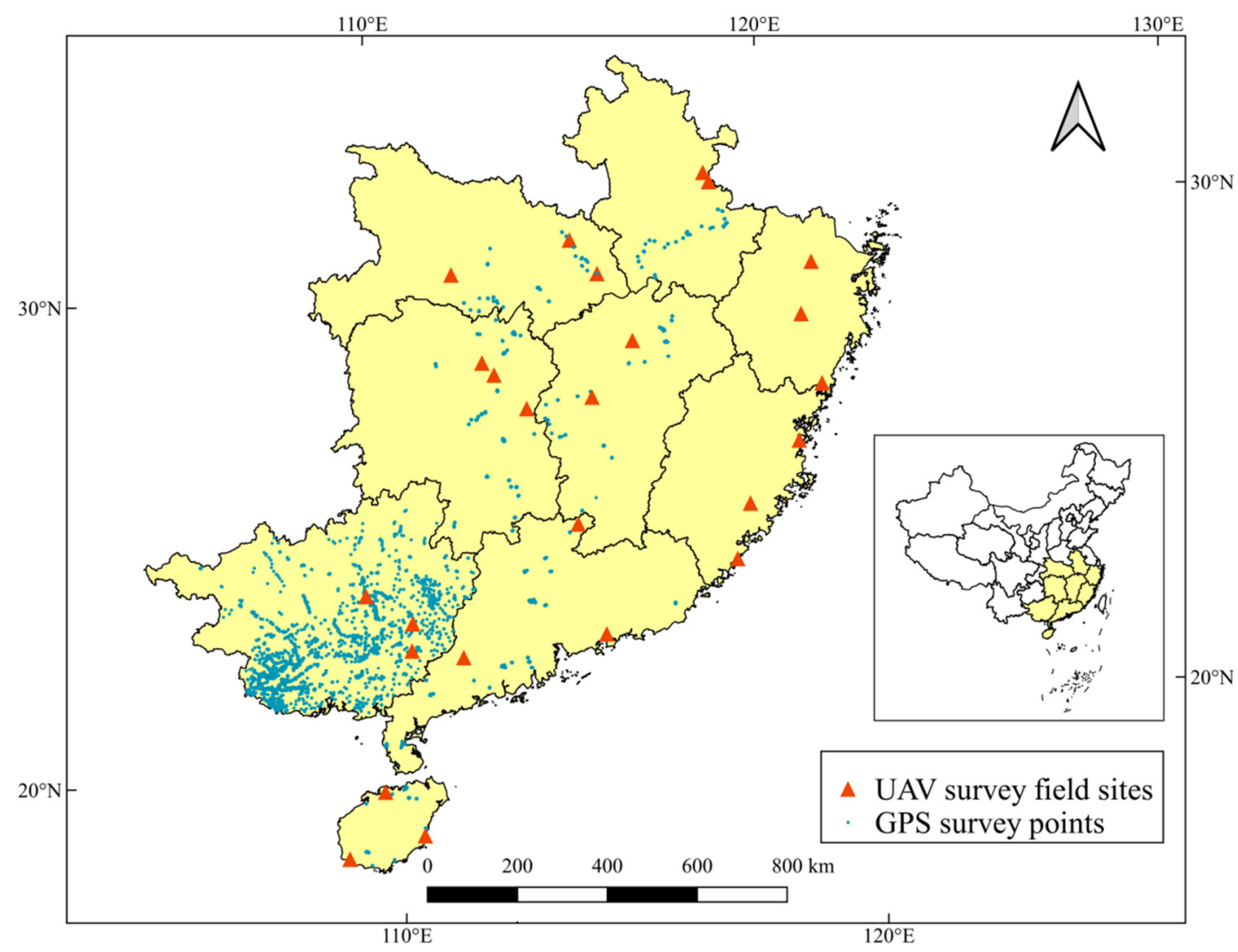

Figure 1. Study area spans nine provinces over China (the yellow region). The solid black lines represent the boundary of the provinces. The red triangles indicate 25 unmanned aerial vehicle (UAV) field survey sites in 2018, and each site covers $1 \mathrm{~km}^{2}$ field area. The blue dots indicate GPS survey points from 2018 to 2020 .

\subsection{Time-Weighted Dynamic Time Warping Method}

In this study, we used the time-weighted dynamic time warping (TWDTW) method to identify the planting area of early rice and late rice. The TWDTW is an upgraded version of the DTW algorithm [48,49]. The DTW algorithm calculates the degree of dissimilarity between two time series (we assume the satellite pixel time series $X$ is the known early rice or late rice field and series $Y$ is that of an unknown land cover pixel) by warping the series $Y$ by adjusting the time dimension and find the minimally modified path to $X$, which represents the degree of dissimilarity between the two series. Considering the phenological changes of different land covers, Maus, et al. [50] optimized the DTW with a time constraint to develop TWDTW, which avoids excessive warping and thus improves the reliability of the DTW method for crop area recognition [31]. 


\subsection{Methods for Identifying Double-Season Paddy Rice Fields}

To identify planting areas of early rice and late rice, we need to distinguish them from other land cover types, including non-vegetated land, forest, grassland, other croplands, and water-related cover types. Non-vegetated land includes built-up and barren surfaces. This study used the FROM-GLC10 dataset (see Section 2.6), which classifies non-vegetated land surfaces, forest and grassland with high accuracy [51], to mask them out and exclude them from further processing. To distinguish double-season rice from other crops and water-related cover types, we used the TWDTW method to compare phenological features extracted from seasonal variations of SAR signals.

The definition of rice growth stages is a prerequisite for identifying paddy rice [52]. The growth of rice is commonly divided into four stages [53-55]: (1) The nursery stage ( -1 month, from sowing to transplanting); (2) the vegetative stage (1.5-3 months, from transplanting to panicle initiation, including tillering); (3) the reproductive stage ( -1 month, from panicle initiation to flowering, including stem elongation, panicle extension and flowering); (4) the ripening stage ( -1 month, from flowering to full maturity, including milk stage, dough stage, and mature grain). To highlight the flooding signal and simplify the description of rice growth stages, based on the above four stages, the growth of rice was divided into three stages for this study (Figures 2 and 3): (1) The flooding-transplanting stage (the nursery stage); (2) the growing stage (the vegetative and reproductive stage); (3) the harvest stage (the ripening stage). The rice cropping calendar (Figure 3) was obtained from the field surveys that were conducted from 2018 to 2020 (Section 2.5).

The most important phenological feature of paddy rice is the mixture of surface water and rice seedlings. During the flooding-transplanting stage, the rice canopy is not closed, and surface water contributes substantially to the satellite signals. Water bodies are a specular reflector of the radar pulse of SAR systems, resulting in a minimal or no signal returned to the satellite [41,42]. During the flooding-transplanting stage, the fields of paddy rice are a mix of flooded soils and sparse rice plants, and therefore, the $\mathrm{VH}$ (dual-band cross-polarization, vertical transmit/horizontal receive) backscatter coefficient of SAR is quite lower than that of other stages and natural vegetation [56,57]. Subsequently, the $\mathrm{VH}$ of rice increases sharply with the growth of rice plants. Therefore, the temporal changes of $\mathrm{VH}$ show a "V"-shape curve through the flooding-transplanting and early growing stages (Figure 2).

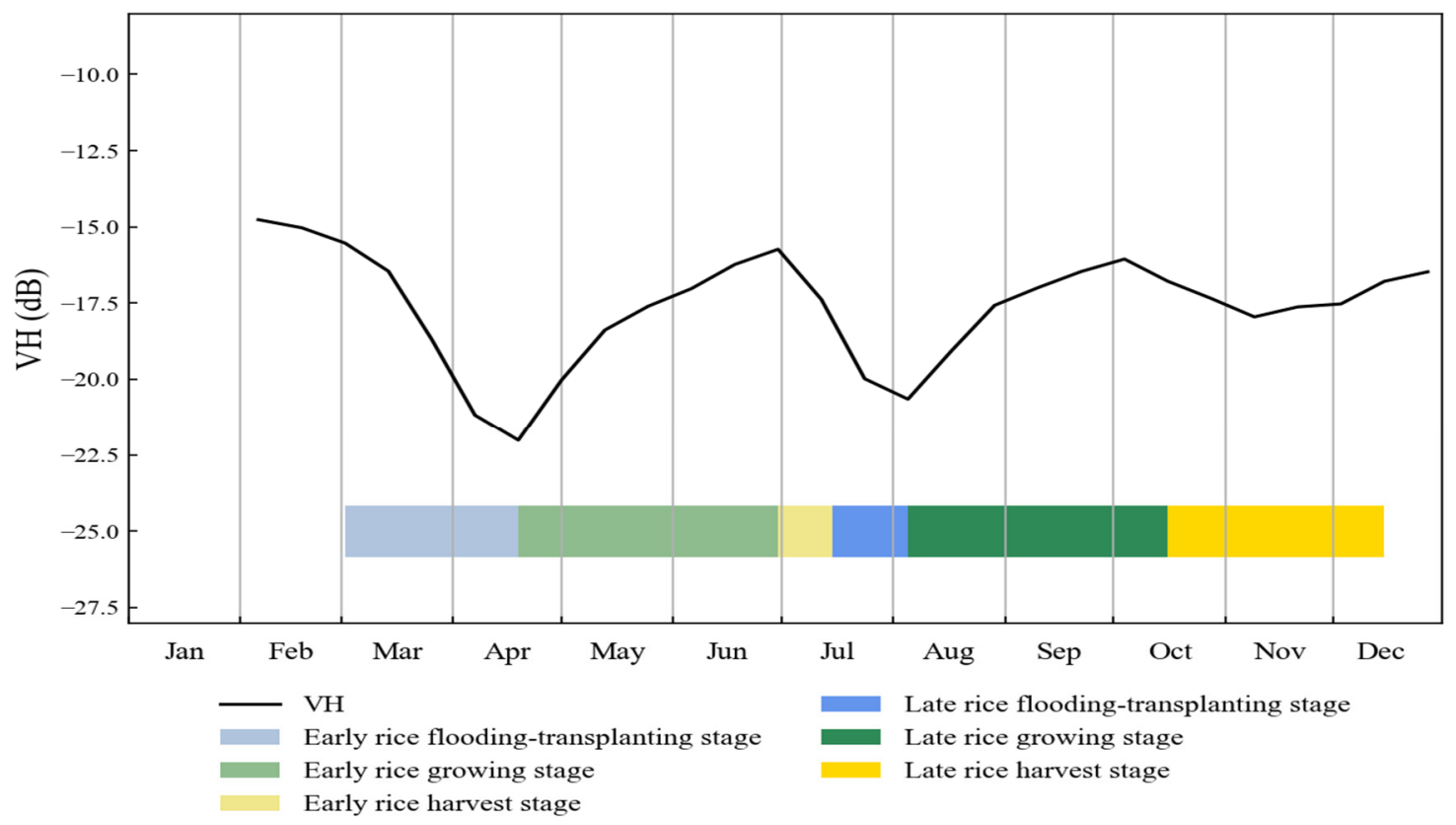

Figure 2. The temporal series of satellite-based VH at a double-season paddy rice sample site. VH: Dual-band crosspolarization vertical transmit/horizontal receive backscatter coefficient of SAR. 


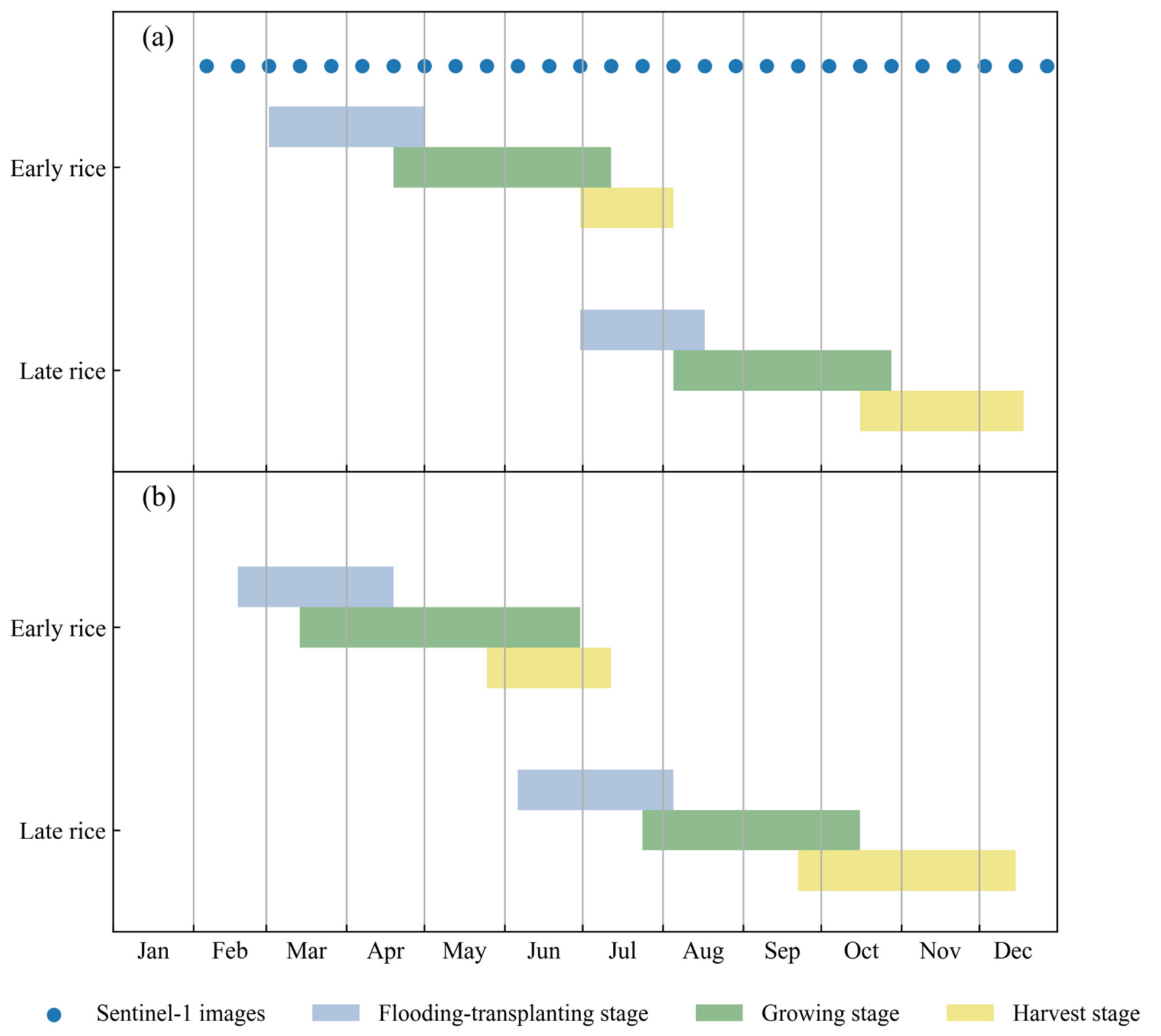

Figure 3. Rice cropping calendar and Sentinel-1 image acquisition dates at Guangdong, Guangxi, Hunan, Jiangxi, Fujian provinces, Hubei, Anhui, Zhejiang provinces (a) and Hainan province (b).

Based on the unique temporal features of $\mathrm{VH}$ during the early growth periods (Figure 2), this study used TWDTW to compare the VH curve of a given pixel to that of the standard curve retrieved from known rice fields. Dissimilarity values were calculated to indicate the seasonal change differences of $\mathrm{VH}$ between each unknown pixel and known paddy rice pixel. Pixels with lower dissimilarity values have a higher probability of being paddy rice. In this study, we used the statistical area of paddy rice at the province level to determine the thresholds of dissimilarity. Specifically, we selected $\mathrm{N}$ pixels with the lowest dissimilarity values as paddy rice in a given province, with the total area of all $\mathrm{N}$ pixels equal to the census area of paddy rice in the investigated province. However, the timing of the flooding-transplanting stage of the same kind of paddy rice vary throughout the region, owing to the differences in environments, topography and planting system. Therefore, we shifted the standard VH curve through the potential flooding-transplanting and early growing stages of rice (Figure 3 ). 
We used a simple random sampling approach to select 100 field investigated paddy rice pixels in each province and extracted the time series of the $\mathrm{VH}$ curves during the potential flooding-transplanting and early growing stages. Then, we first detected the lowest values of the VH curves from the flooding-transplanting stages to first half periods of the growing stages of early rice and generated the standard $\mathrm{VH}$ curves for five time periods: the time of the lowest $\mathrm{VH}$ value $\left(\mathrm{T}_{\mathrm{LOW}}\right)$, two times prior to $\mathrm{T}_{\mathrm{LOW}}$ and two times after $\mathrm{T}_{\mathrm{LOW}}$, totally covering about 60 days (Figure 4a, red curve). In the investigated pixels, we used a moving window covering 60 days to extract the time series of $\mathrm{VH}$ from the floodingtransplanting stages to first half periods of the growing stages (Figure 3 ) and calculated the dissimilarity values by comparing them with the above 100 standard curves. Figure 4 shows how to calculate the dissimilarity values of an unknown pixel compared with one standard curve of early rice in Guangdong Province. Firstly, we generated a standard curve of early rice from a known double-season rice pixel (Figure $4 \mathrm{a}$, red curve). Secondly, we extracted the time series of $\mathrm{VH}$ from the unknown pixel with a moving window covering 60 days (Figure $4 b-d$ ). In Guangdong Province, the flooding-transplanting stages to the first half periods of the growing stages were from March to April (Figure 3a), so there were three moving windows-18 Feb to 7 Apr (Figure 4b, green curve), 2 Mar to 19 Apr (Figure 4c, green curve), 14 Mar to 1 May (Figure 4d, green curve); we extracted three time series from the same pixel (Figure $4 b-d$, green curve). Thirdly, based on TWDTW, we calculate the dissimilarity values by comparing the standard curve (Figure 4a, red curve) with each of the three time series (Figure $4 b-d$, green curve). As a result, we obtained three dissimilarity values. Comparing with 100 standard curves, we calculated a total of 300 dissimilarity values for each unknown pixel, and the lowest dissimilarity value (ERmin) was selected to represent the degree of dissimilarity between the unknown pixels and known early rice pixels.

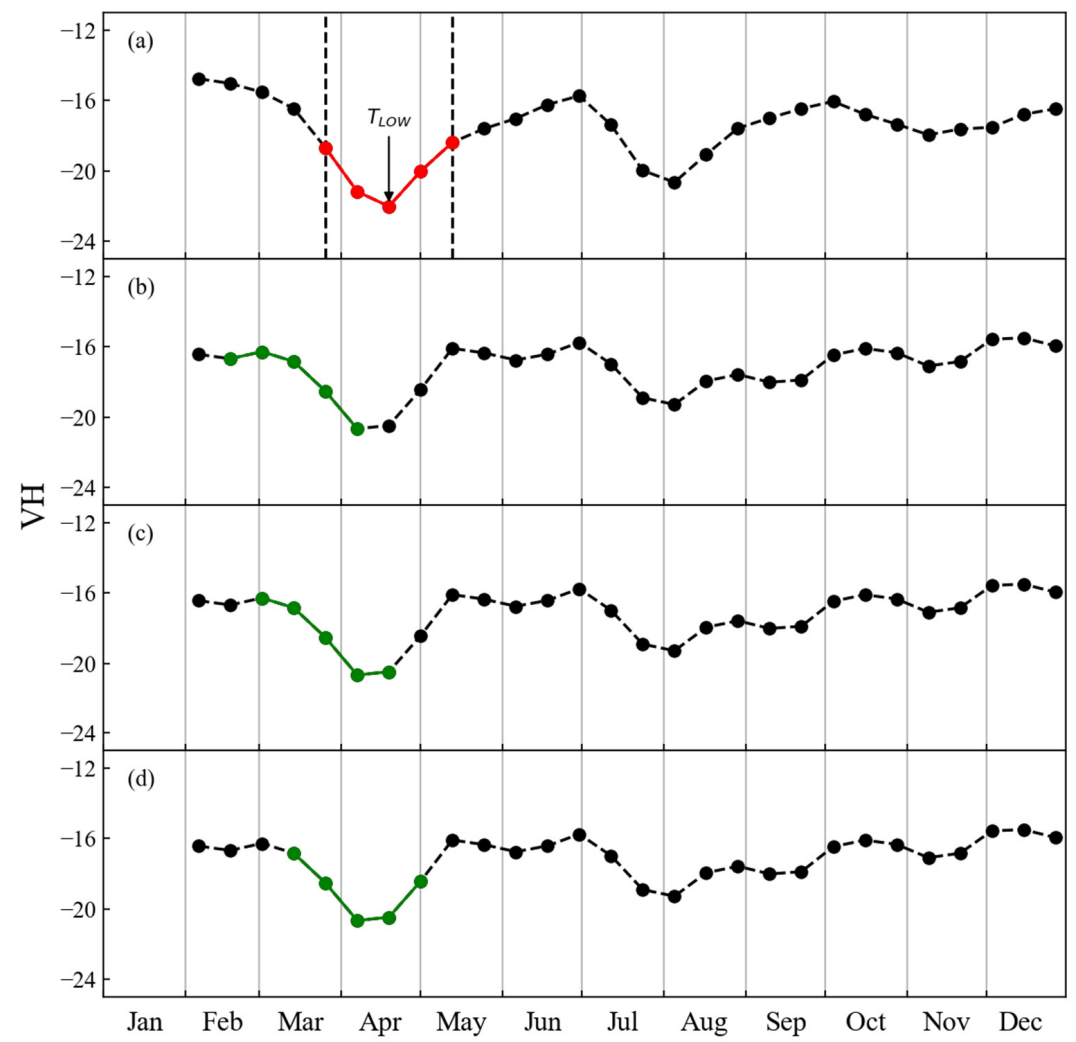

Figure 4. The temporal series of $\mathrm{VH}$ at a double-season paddy rice pixel (a) and red curve means a standard VH curve covering five times (60 days). The temporal series of $\mathrm{VH}$ at an unknown pixel applied with three moving windows respectively $(\mathbf{b}-\mathbf{d})$ and green curve means an extracted unknown curve covering five times (60 days). 
Following the same process, we also calculated the lowest dissimilarity value of late rice (LRmin) by comparing the standard $\mathrm{VH}$ curves of late rice with the $\mathrm{VH}$ curve of unknown pixels. The fields planting early rice also plant late rice in the same year, so the study used the sum of ERmin and LRmin to represent the degree of dissimilarity between the unknown pixel and known early rice pixels (ERdist). We first identified planting areas of early rice-late rice type (i.e., Type I) based on the TWDTW method by comparing ERdist of all pixels. Then we chose LRmin to represent the degree of dissimilarity between the unknown pixel and known other crops-late rice pixels (LRdist). In each province, the area differences of late rice and early rice were used to determine the thresholds of LRdist for identifying planting areas of other crops-late rice type (i.e., Type II) based on the TWDTW method.

\subsection{Satellite Data}

This study used the Ground Range Detected (GRD, Level-1) product from Sentinel-1, which has dual-polarized vertical transmission with VV (vertical transmit/vertical receive) and $\mathrm{VH}$ (vertical transmit/horizontal receive) bands. We composited the VH data from 2016 to 2020 into corresponding 12-day mean images. Each image was processed to perform thermal noise removal, radiometric calibration, terrain correction and obtain the backscatter coefficient on the Google Earth Engine platform. Even when standard noise-reduction techniques are applied, SAR images contain residual speckle noise due to the interferences between adjacent backscatter returns. To further correct the SAR images for speckle noise, a Savitzky-Golay (SG) filter was applied on the temporal axis for each pixel to smooth the time series. The window size was set to 5 , the order and polynomial degree were set to 2 in the SG filter.

\subsection{Field Data}

To obtain the standard seasonal change curve of early rice and late rice, and evaluate the identification accuracy at the pixel level, this study conducted several field surveys during the growing season of early rice and late rice from 2018 to 2020 (Figure 1). First, at 25 investigated sites, we used an unmanned aerial vehicle (UAV) (eBee Extended User Manual, 2015) to take field images in 2018. The UAV was equipped with an RGB camera (Canon S110), which acquired images with a resolution finer than 0.1-m, covering an area of about $1 \mathrm{~km}^{2}$. These images were classified into paddy rice, other crops, natural vegetation and non-vegetation types based on an object-oriented supervised classification as well as field investigations. When using UAV images to generate $10 \mathrm{~m}$ surveyed pixels, pixels with $100 \%$ double-season rice inside were defined as double-season rice pixels, while $100 \%$ non-double-season rice inside were defined as non-double-season rice pixels. In total, these aerial images contained 126,858 pixels at $10 \mathrm{~m}$ spatial resolution, of which 48,326 pixels were double-season rice samples, and 78,532 were non-double-season rice samples. Then, we surveyed 18,352 field samples with a hand-held GPS over seven provinces during 2018 and 2020, of which 6127 pixels were double-season rice samples, and 12,225 were non-double-season rice samples (Figure 1).

\subsection{Land-Cover Dataset and Agricultural Census Data}

The Finer Resolution Observation and Monitoring of Global Land Cover (FROM-GLC) product with $10 \mathrm{~m}$ resolution was used as a mask to remove non-vegetated land surfaces, forest and grassland [51]. Agricultural census area data of early rice and late rice at the province level during the period of 2016-2019 were acquired from the National Bureau of Statistics of China (2017-2020). The data at the county level during the period of 2016-2019 were acquired from the official website of each municipal-level city statistics bureau.

\subsection{Accuracy Assessment}

The accuracy of identified double-season rice planting areas was evaluated both at pixel and regional scales. First, based on a total of 145,210 ground truth samples retrieved 
from field surveys, the study calculated producer's accuracy (PA), user's accuracy (UA) and overall accuracy (OA) to investigate the effectiveness of the method. PA indicates the proportion of ground truth samples properly classified as the target class, and UA indicates the proportion of identified double rice on the classification map that is actually present on the ground. OA is calculated as the ratio of correctly identified samples to total field samples.

In addition, the planting areas of early rice and late rice identified in this study were compared with those obtained from agricultural statistical data at the county level. Three statistical metrics were used:

(1) The coefficient of determination $\left(R^{2}\right)$, representing how much variation of statistical area is explained by the identified area.

(2) Root mean square error (RMSE), measuring the deviation between identified and statistical areas, was computed as:

$$
\mathrm{RMSE}=\sqrt{\frac{1}{n} \sum_{i=1}^{n}\left(I A_{i}-S A_{i}\right)^{2}}
$$

where $S A_{i}$ and $I A_{i}$ are the statistical area and identified area of the $i$-th county respectively, and $\mathrm{n}$ indicates the number of counties in a given province. The unit of RMSE referred to in this study is thousand hectares $\left(10^{3} \mathrm{ha}\right)$, and to simplify the description, only the values of RMSE are described below.

(3) The relative mean absolute errors (RMAE), quantifying the difference between identified and statistical areas, was calculated as:

$$
\mathrm{RMSE}=\frac{\sum_{i=1}^{n}\left|S A_{i}-I A_{i}\right|}{\sum_{i=1}^{n} S A_{i}} \times 100 \%
$$

\section{Results}

This study generated maps of early rice and late rice over nine provinces in China from 2016 to 2020, and the distribution maps in 2018 are shown as an example (Figure 5). With the updating of the satellite data records, the same method can be used to update the distribution maps of early rice and late rice by the end of each year.
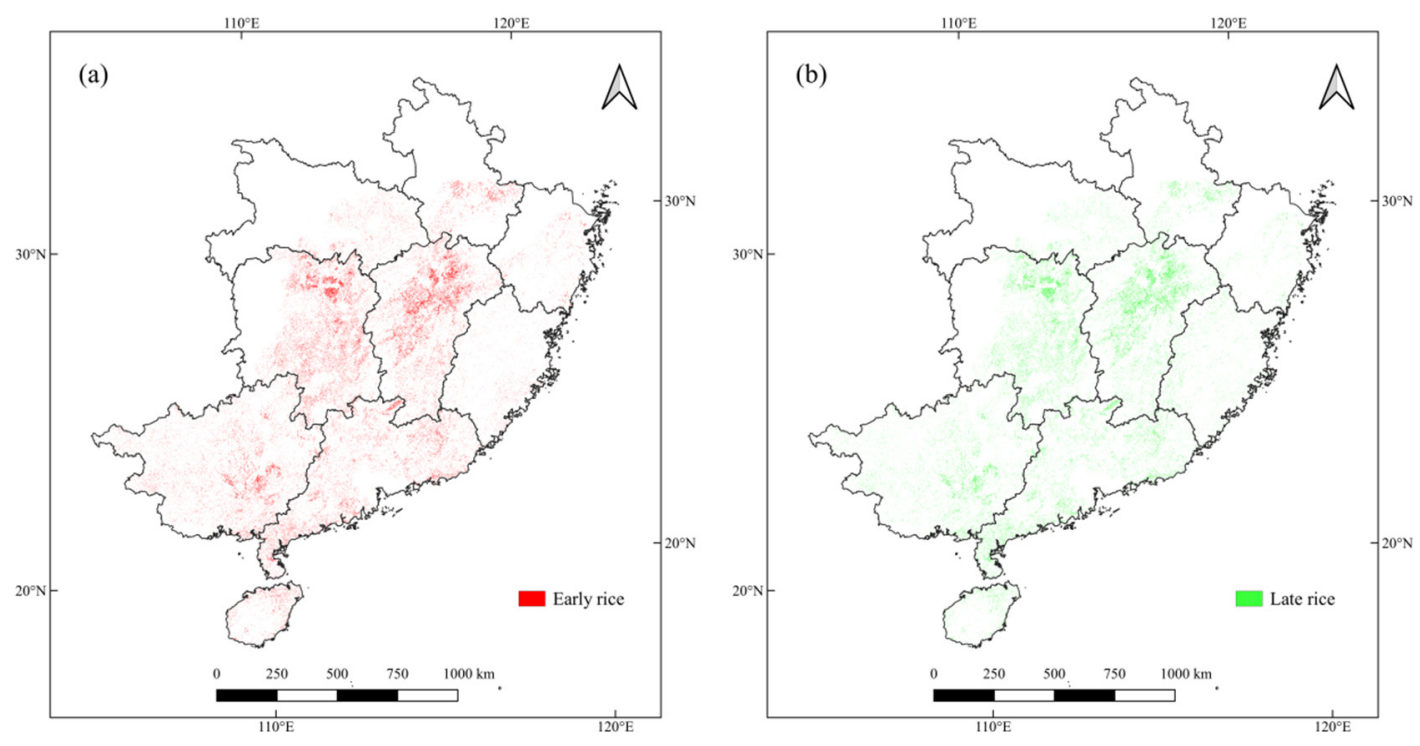

Figure 5. Distribution map of early rice (a) and late rice (b) in 2018.

Our method shows a good performance in identifying the planting areas of early rice and late rice over all the nine provinces. Based on the field survey samples containing 
a variety of ground objects, the overall identification accuracy $(\mathrm{OA})$ varied among the nine provinces, ranging from $88.07 \%$ to $95.97 \%$ for early rice (Table 2), and from $88.25 \%$ to $95.68 \%$ for late rice (Table 3). The user's accuracy (UA) and producer's accuracy (PA) were high in most provinces. However, for early rice, Hubei Province had the lowest UA of $63.07 \%$ and the lowest PA of $73.48 \%$ (Table 2). For late rice, Hubei Province achieved the lowest UA of $60.39 \%$ and the lowest PA of $74.11 \%$ (Table 3 ).

Table 2. Confusion matrix for the identification map of planting areas of early rice in nine provinces from 2018 to 2020.

\begin{tabular}{|c|c|c|c|c|c|c|}
\hline Province & Class & Early Rice $^{1}$ & Non-Early Rice ${ }^{1}$ & $\begin{array}{c}\text { User's } \\
\text { Accuracy }\end{array}$ & $\begin{array}{c}\text { Producer's } \\
\text { Accuracy }\end{array}$ & $\begin{array}{l}\text { Overall } \\
\text { Accuracy }\end{array}$ \\
\hline \multirow{2}{*}{ Guangdong } & Early rice ${ }^{2}$ & 11,610 & 1349 & $89.59 \%$ & $89.60 \%$ & \multirow{2}{*}{$88.07 \%$} \\
\hline & Non-Early rice ${ }^{2}$ & 1347 & 8295 & $86.03 \%$ & $86.01 \%$ & \\
\hline \multirow{2}{*}{ Guangxi } & Early rice & 6796 & 1051 & $86.61 \%$ & $81.15 \%$ & \multirow{2}{*}{$88.17 \%$} \\
\hline & Non-Early rice & 1579 & 12,802 & $89.02 \%$ & $92.41 \%$ & \\
\hline \multirow{2}{*}{ Hainan } & Early rice & 5479 & 639 & $89.56 \%$ & $83.75 \%$ & \multirow{2}{*}{$90.44 \%$} \\
\hline & Non-Early rice & 1063 & 10,629 & $90.91 \%$ & $94.33 \%$ & \\
\hline \multirow{2}{*}{ Hunan } & Early rice & 12,249 & 2150 & $85.07 \%$ & $93.89 \%$ & \multirow{2}{*}{$90.50 \%$} \\
\hline & Non-Early rice & 797 & 15,840 & $95.21 \%$ & $88.05 \%$ & \\
\hline \multirow{2}{*}{ Jiangxi } & Early rice & 7219 & 1027 & $87.55 \%$ & $97.30 \%$ & \multirow{2}{*}{$91.88 \%$} \\
\hline & Non-Early rice & 200 & 6674 & $97.09 \%$ & $86.66 \%$ & \\
\hline \multirow{2}{*}{ Fujian } & Early rice & 771 & 252 & $75.37 \%$ & $81.42 \%$ & \multirow{2}{*}{$93.73 \%$} \\
\hline & Non-Early rice & 176 & 5629 & $96.97 \%$ & $95.72 \%$ & \\
\hline \multirow{2}{*}{ Zhejiang } & Early rice & 2081 & 277 & $88.25 \%$ & $74.83 \%$ & \multirow{2}{*}{$91.75 \%$} \\
\hline & Non-Early rice & 700 & 8790 & $92.62 \%$ & $96.94 \%$ & \\
\hline \multirow{2}{*}{ Hubei } & Early rice & 579 & 339 & $63.07 \%$ & $73.48 \%$ & \multirow{2}{*}{$95.97 \%$} \\
\hline & Non-Early rice & 209 & 12,471 & $98.35 \%$ & $97.35 \%$ & \\
\hline \multirow{2}{*}{ Anhui } & Early rice & 1403 & 101 & $93.28 \%$ & $87.80 \%$ & \multirow{2}{*}{$92.85 \%$} \\
\hline & Non-Early rice & 195 & 2442 & $92.61 \%$ & $96.03 \%$ & \\
\hline
\end{tabular}

${ }^{1}$ Number of field surveyed samples. ${ }^{2}$ Number of identified samples.

Table 3. Confusion matrix for the identification map of planting areas of Late rice in nine provinces from 2018 to 2020.

\begin{tabular}{|c|c|c|c|c|c|c|}
\hline Province & Class & Late Rice $^{1}$ & Non-Late Rice ${ }^{1}$ & $\begin{array}{c}\text { User's } \\
\text { Accuracy }\end{array}$ & $\begin{array}{c}\text { Producer's } \\
\text { Accuracy }\end{array}$ & $\begin{array}{l}\text { Overall } \\
\text { Accuracy }\end{array}$ \\
\hline \multirow{2}{*}{ Guangdong } & Late rice $^{2}$ & 11,751 & 1450 & $89.02 \%$ & $90.69 \%$ & \multirow{2}{*}{$88.25 \%$} \\
\hline & Non-Late rice ${ }^{2}$ & 1206 & 8194 & $87.17 \%$ & $84.96 \%$ & \\
\hline \multirow{2}{*}{ Guangxi } & Late rice & 6895 & 1099 & $86.25 \%$ & $82.33 \%$ & \multirow{2}{*}{$88.40 \%$} \\
\hline & Non-Late rice & 1480 & 12,754 & $89.60 \%$ & $92.07 \%$ & \\
\hline \multirow{2}{*}{ Hainan } & Late rice & 5479 & 639 & $89.56 \%$ & $83.75 \%$ & \multirow{2}{*}{$90.44 \%$} \\
\hline & Non-Late rice & 1063 & 10,629 & $90.91 \%$ & $94.33 \%$ & \\
\hline \multirow{2}{*}{ Hunan } & Late rice & 12,261 & 2206 & $84.75 \%$ & $93.98 \%$ & \multirow{2}{*}{$90.36 \%$} \\
\hline & Non-Late rice & 785 & 15,784 & $95.26 \%$ & $87.74 \%$ & \\
\hline \multirow{2}{*}{ Jiangxi } & Late rice & 7238 & 1455 & $83.26 \%$ & $97.56 \%$ & \multirow{2}{*}{$89.18 \%$} \\
\hline & Non-Late rice & 181 & 6246 & $97.18 \%$ & $81.11 \%$ & \\
\hline \multirow{2}{*}{ Fujian } & Late rice & 771 & 252 & $75.37 \%$ & $81.42 \%$ & \multirow{2}{*}{$93.73 \%$} \\
\hline & Non-Late rice & 176 & 5629 & $96.97 \%$ & $95.72 \%$ & \\
\hline \multirow{2}{*}{ Zhejiang } & Late rice & 2082 & 280 & $88.15 \%$ & $74.87 \%$ & \multirow{2}{*}{$91.74 \%$} \\
\hline & Non-Late rice & 699 & 8787 & $92.63 \%$ & $96.91 \%$ & \\
\hline \multirow{2}{*}{ Hubei } & Late rice & 584 & 383 & $60.39 \%$ & $74.11 \%$ & \multirow{2}{*}{$95.68 \%$} \\
\hline & Non-Late rice & 204 & 12,427 & $98.38 \%$ & $97.01 \%$ & \\
\hline \multirow{2}{*}{ Anhui } & Late rice & 1403 & 106 & $92.98 \%$ & $87.80 \%$ & \multirow{2}{*}{$92.73 \%$} \\
\hline & Non-Late rice & 195 & 2437 & $92.59 \%$ & $95.83 \%$ & \\
\hline
\end{tabular}

${ }^{1}$ Number of field surveyed samples. ${ }^{2}$ Number of identified samples.

In addition, this method accurately estimated the areas of early rice and late rice compared to the available agricultural statistical data at the county level for all investigated provinces (Figure 6). The maps reproduce well the spatial variations of the planting area of paddy rice. For early rice in each province (Figure 7), the averaged $R^{2}$ over three years 
of 2016-2019 ranged from 0.50 to 0.87 , the averaged RMSE ranged from 1.53 to 6.94 , and the average of RMAE ranged from $22 \%$ to $59 \%$. For Guangdong, Guangxi, Hunan and Jiangxi Provinces, which occupies $85.61 \%$ of the planting area of early rice in China, the classification shows good performance according to three metrics (Figure 7). Fujian and Hubei Province show large classification errors at the county level (Figure 7). For example, the averaged RMAE in Fujian is more than $59 \%$, and $\mathrm{R}^{2}$ is less than 0.50 (Figure 7). Among the four validation years (i.e., 2016-2019), 2016 shows the largest error at the county level (Figure 6).
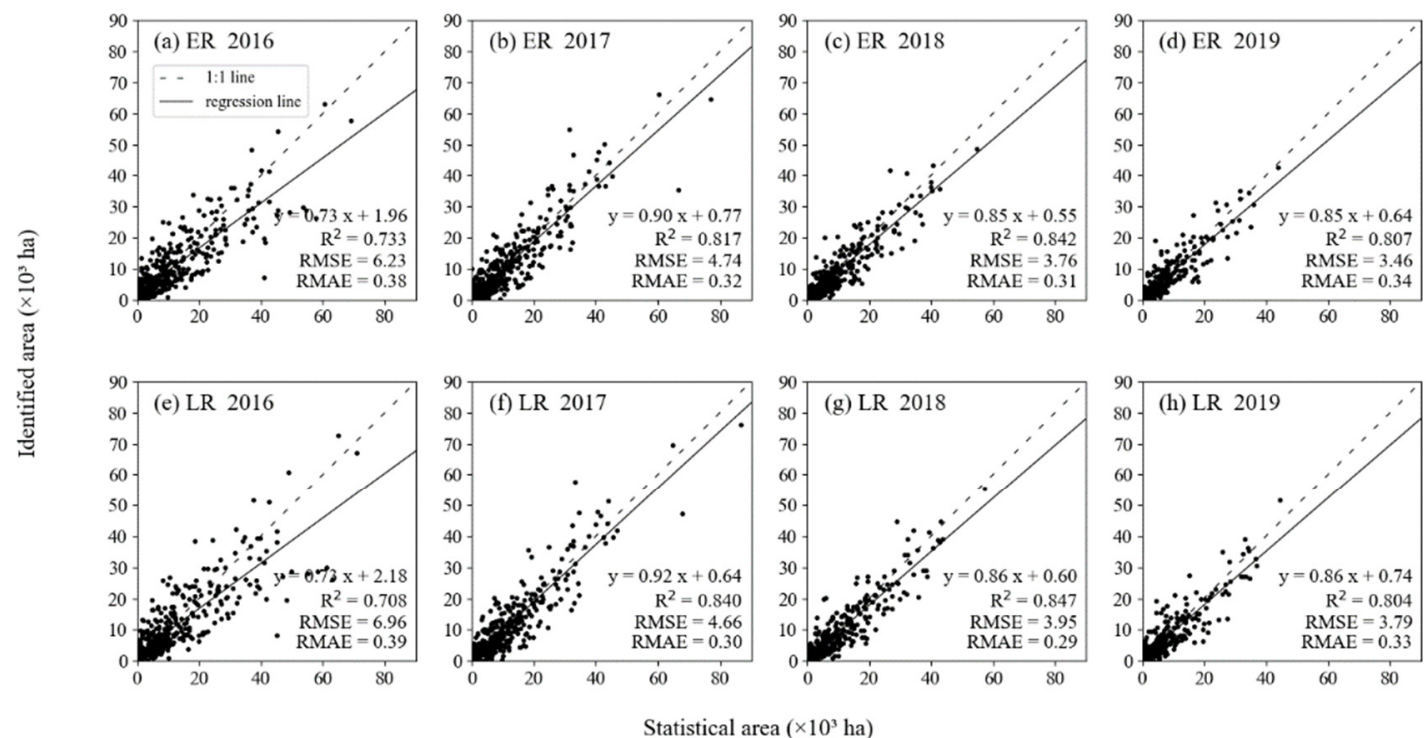

Figure 6. County-level comparison of identified and statistical planting areas from 2016-2019, for early rice (a-d) and late rice $(\mathbf{e}-\mathbf{h})$.

The classification accuracy of late rice is similar to that of early rice over almost all provinces. The averaged $\mathrm{R}^{2}$ ranged from 0.56 to 0.86 , and the averaged RMAE ranged from $23 \%$ to $51 \%$ (Figure 8 ). In four major planting provinces, including Guangdong, Guangxi, Hunan and Jiangxi Provinces, the classification shows high $\mathrm{R}^{2}$ and low identification errors. The largest classification errors are found in Fujian and Hubei Provinces.

To analyze the spatial distribution of isolated patches, we used maps of early rice and late rice for 2018 as an example, and calculated the cumulative area percentage of different patch sizes ranging from 1 pixel to $10^{6}$ pixels per patch (Figure 9). In nine provinces, early rice patches with only one pixel accounted for $2.31 \%$ to $10.59 \%$, but this percentage accounted for $2.31 \%$ to $5.97 \%$ in the major early rice planting zones including Guangdong, Guangxi, Hunan and Jiangxi Provinces. For late rice, patches with only one pixel accounted for $2.11 \%$ to $8.19 \%$ in nine provinces but $2.11 \%$ to $5.82 \%$ in the major late rice planting zones. Considering the cumulative area percentage of early rice patches of 100 pixels, four provinces of the main producing area rank at the bottom, with Guangxi Province with less than $51 \%$; this indicates that the main producing area has mostly large patches, as we would expect for this area. A similar result is found for late rice. It is worth noting that the cumulative area percentage of patches with 100 pixels in Fujian Province drops from $85.29 \%$ of early rice to $52.61 \%$ of late rice. Because early rice-late rice (Type I) only accounts for $46.31 \%$ of the areas of double-season rice in Fujian province (Table 1), this area, and adjacent fields where early rice and other crops are grown during the first cropping season, will plant late rice in the next period. For curves with the cumulative area percentage reaching $100 \%$, four provinces of the main producing area have more large patches, and Jiangxi Province has the largest proportion of large fields. 


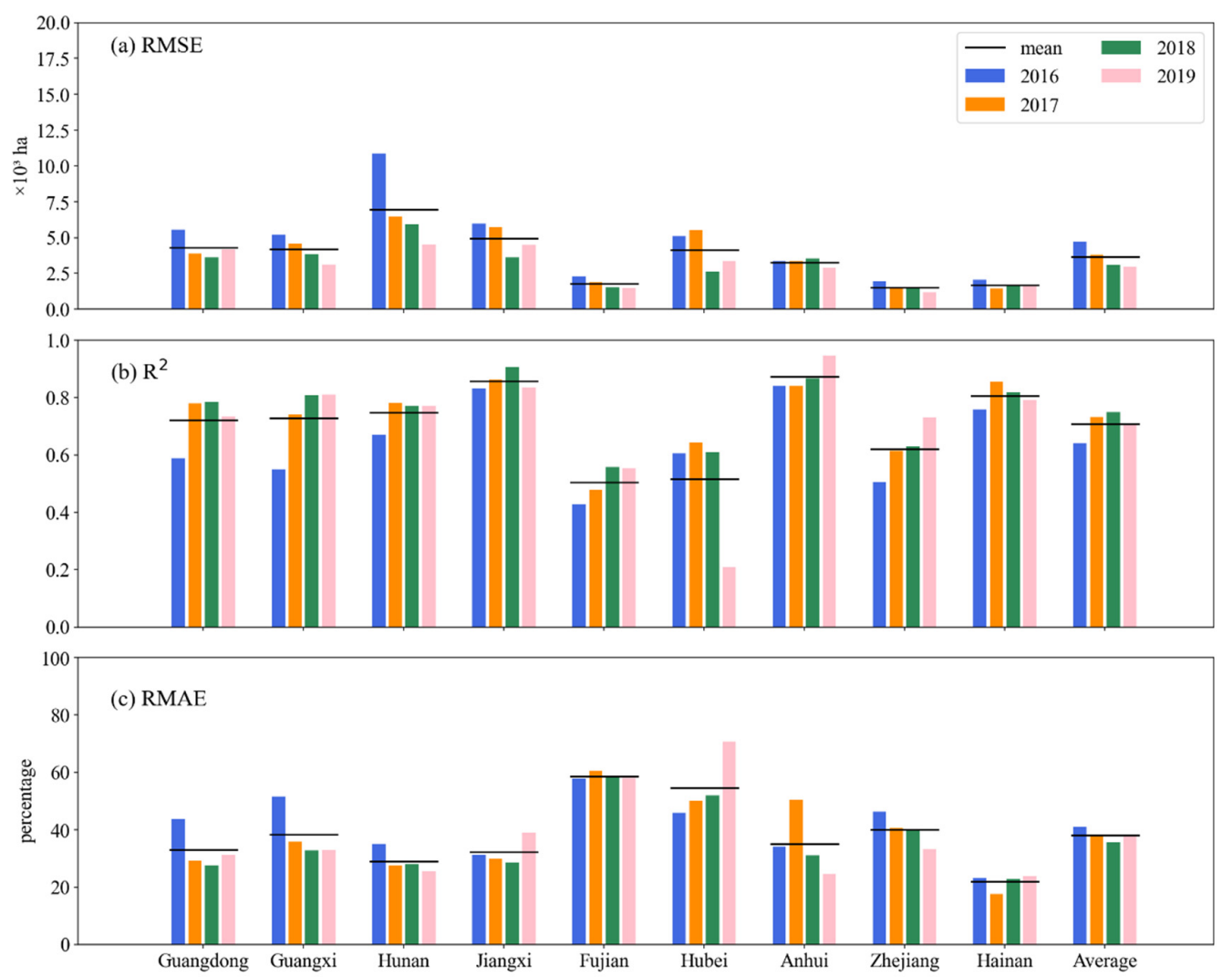

Figure 7. The comparison between identified planting areas of early rice and agricultural census areas at county-level for 2016-2019 in all nine investigated provinces.
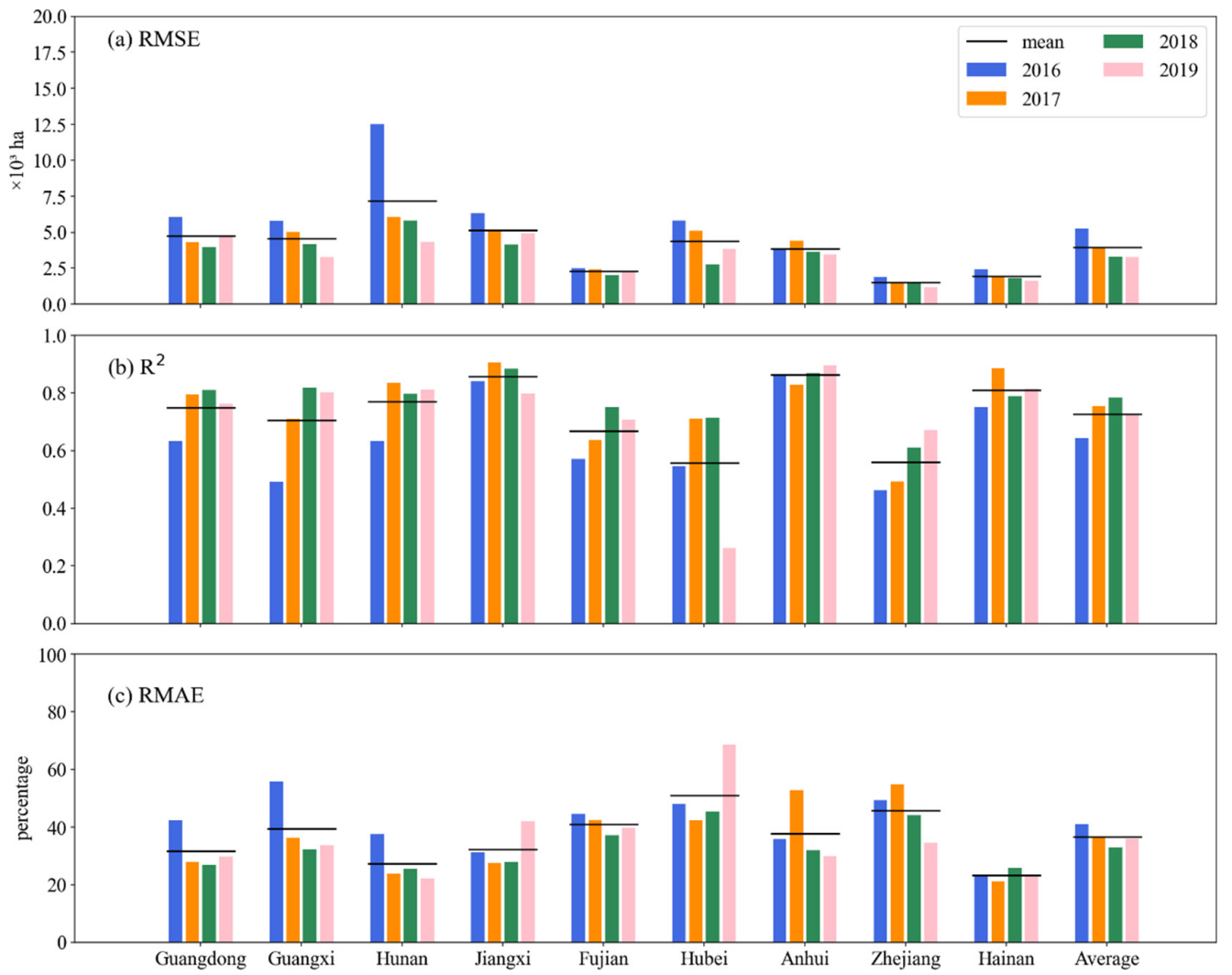

Figure 8. The comparison between identified planting areas of late rice and agricultural census areas at county-level for 2016-2019 in all nine investigated provinces. 


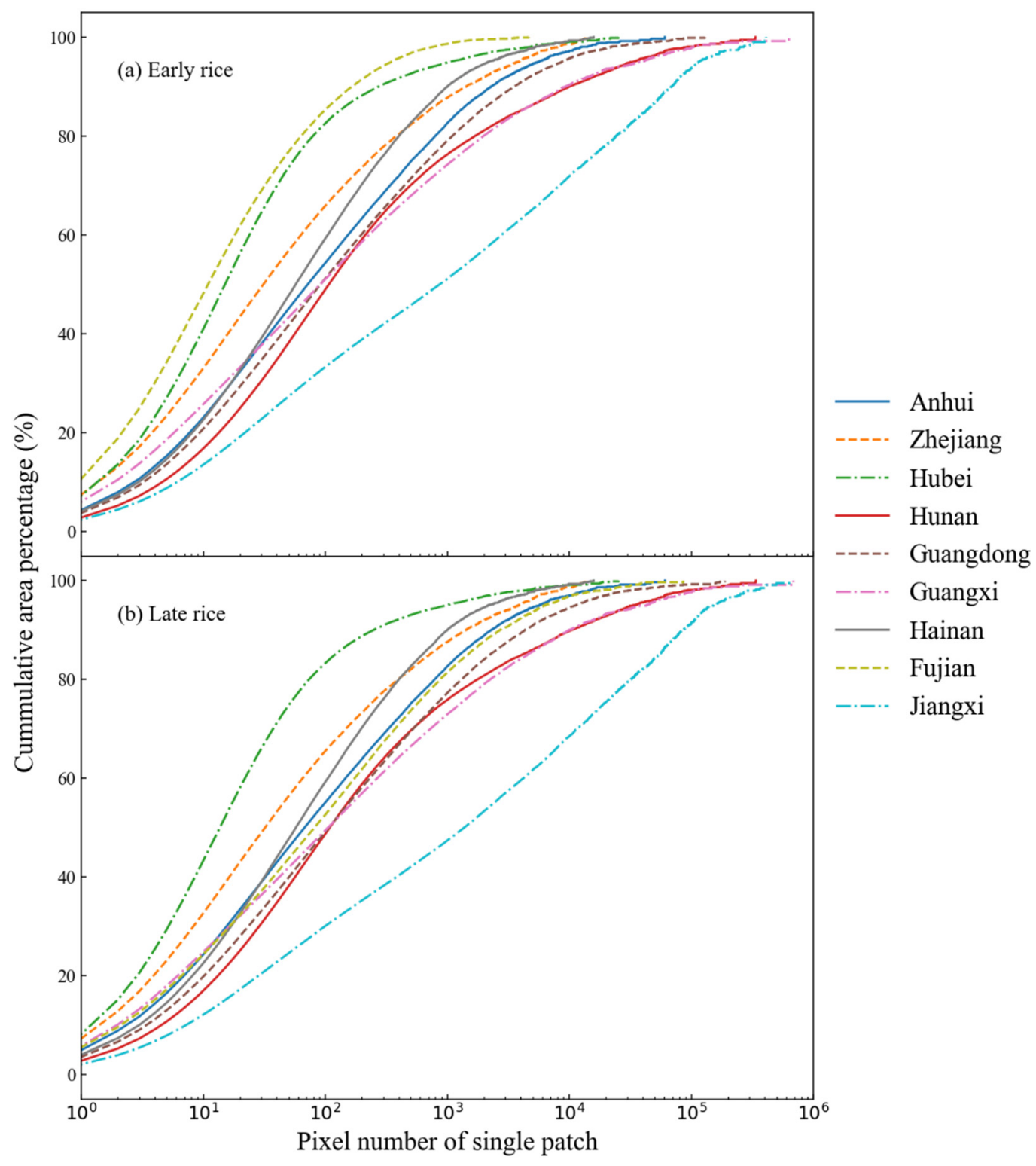

Figure 9. Statistics for patches with different pixel numbers in the distribution map of early rice (a) and late rice (b) in 2018.

\section{Discussion}

Paddy rice is one of the most important crops in the world, and information on its spatial extent is critical for drafting economic and grain subsidy policies. To our knowledge, there are currently no distribution maps for double-season rice of high spatial resolution in China.

In this study, we generated double-season rice distribution maps with a spatial resolution of $10 \mathrm{~m}$ for the period of 2016-2020 based on the TWDTW method. Validations based on field surveys and statistical data indicate that the proposed method accurately identifies the early rice and late rice planting areas over all the nine provinces where most of the planting takes place. Unlike machine learning methods that require a large number of training samples [58], our method only requires a small number of field survey samples to produce the distribution maps of early rice and late rice over nine provinces from 2016 to 2020. Our method demonstrates a great skill for mapping $10 \mathrm{~m}$ early rice and late rice in South China, where the weather is cloudy and rainy during the key phenological 
period, the terrain is mountainous and complex, and fields are fragmented with various planting patterns.

Regional validation (Figures 6, 7c and 8c) shows that the identification accuracy is still low for some of the investigated years and provinces. The identification accuracy is the lowest in 2016 compared to other years and is caused by an inadequate number of Sentinel-1 (Figure 10). Compared to other years, the effective observations in 2016 are only 24 averaged over all nine provinces, which is lower than in other years, when they range from 34 to 40 times. Second, a relatively high RMAE was found in Hubei, Fujian and Guangxi Provinces, where mountainous terrain may be the main cause for the low identification accuracy. For example, in Fujian Province, according to statistical data, 64\% of the paddy rice fields are located in the mountainous area of western Fujian province, including Longyan, Sanming and Nanan prefecture-level cities. The SAR backscatter signal is corrupted by the terrain effect, even when complex radiometric terrain corrections are implemented. In addition, mountainous paddy rice fields are small and fragmented, introducing several mixed $10 \mathrm{~m}$ pixels without typical VH characteristics $[59,60]$.

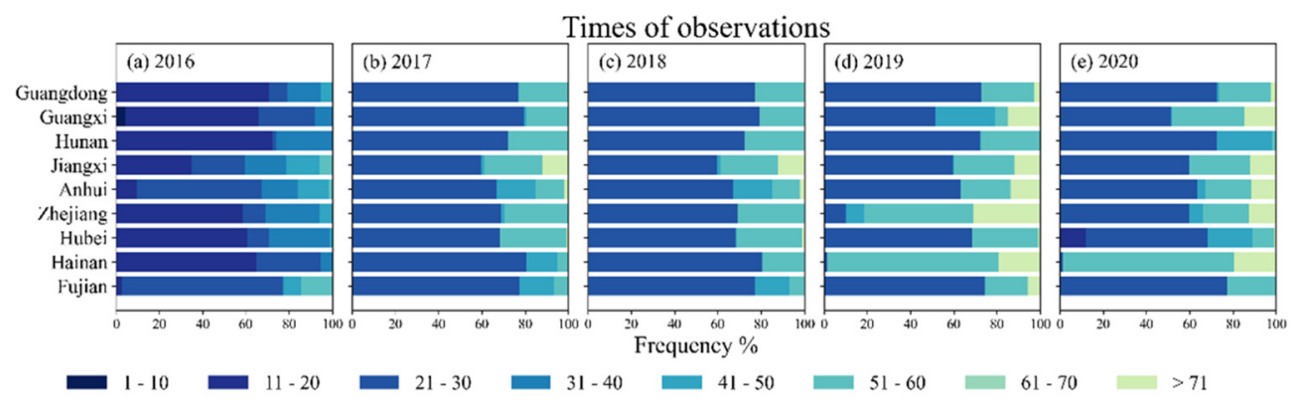

Figure 10. Times of Sentinel-1 original observations from February to December during 2016 (a) to 2020 (e).

The future use of satellite data with higher spatial and temporal resolutions are expected to further improve classification accuracy because higher spatial resolution data will help reduce the number of mixed pixels in mountainous areas and higher temporal resolution data will more easily capture the weak flooding signals resulting from the rapid harvesting and replanting cycles (i.e., the harvest stage of early rice and floodingtransplanting stage of late rice). Future work will also need to use other satellite data to produce rice maps before 2016 when Sentinel-1 data was not available yet. However, data such as those from TerraSAR-X data have a high spatial resolution (3-10 m) and temporal resolution (11-day) but are expensive to use for rice monitoring over large regions. TerraSAR-X data have been used for rice monitoring over smaller regions, like in Spain [61], Mekong Delta, Vietnam [62] and Sanjiang Plain in Heilongjiang Province, Northeast China [63]. Finally, the method can be applied for mapping different planting systems of paddy rice over large regions (i.e., the single-, double- and triple-season paddy rice). The most important difference between the different planting systems is the number of flooding signals in a year. For example, the triple-season paddy rice will have three "V"-shape curves of VH data owing to planting paddy rice three times in a year.

\section{Conclusions}

Based on the available Sentinel-1 images and a time-weighted dynamic time warping (TWDTW) method, this study produced the first $10 \mathrm{~m}$ spatial resolution early rice and late rice maps over nine provinces of South China, which account for more than $99 \%$ of the planting area of double-season paddy rice in China. Based on 145,210 survey samples, the overall identification accuracy for early rice and late rice were $90.74 \%$ and $90.46 \%$, respectively. Compared with the agricultural statistical data at the county level over nine provinces, the maps explain $79.20 \%$ and $78.96 \%$ of the spatial variability of early and late rice. The timely and accurate $10 \mathrm{~m}$ double-season rice maps provide critical information for quantifying methane emissions, water resource management and ensuring food security. 
The maps are also useful for commercial companies to make rice production plans or conduct futures transactions while for farmers to formulate personal production plans.

Author Contributions: Conceptualization, T.Y. and W.Y.; data curation, B.P., Y.Z., R.S., W.Z., J.D. and H.M.; formal analysis, B.P., Y.Z., R.S., W.Z., J.D. and H.M.; funding acquisition, T.Y. and W.Y.; investigation, B.P. and Y.Z.; methodology, B.P. and W.Y.; project administration, T.Y. and W.Y.; software, Y.Z., W.Z., J.D. and H.M.; supervision, T.Y. and W.Y.; validation, B.P. and R.S.; visualization, R.S.; writing—original draft, B.P.; writing—review and editing, T.Y. and W.Y. All authors have read and agreed to the published version of the manuscript.

Funding: This research has been supported by the China National Funds for Distinguished Young Scientists (grant no. 41925001), the National Youth Top-Notch Talent Support Program (grant no. 201548), the Changiiang Young Scholars Program of China (grant no. Q2016161), and the Fundamental Research Funds for the Central Universities (grant no. 19lgjc02).

Data Availability Statement: The data presented in this study are available in the article.

Acknowledgments: The authors would like to thank the reviewers and editors for their constructive comments.

Conflicts of Interest: The authors declare no conflict of interest.

\section{References}

1. FAOSTAT. FAO Statistical Databases (Food and Agriculture Organization of the United Nations) Databases-UW-Madison Libraries. 2020. Available online: http:/ / digital.library.wisc.edu/1711.web/faostat (accessed on 12 November 2021).

2. Kuenzer, C.; Knauer, K. Remote sensing of rice crop areas. Int. J. Remote Sens. 2013, 34, 2101-2139. [CrossRef]

3. Piedelobo, L.; Hernández-López, D.; Ballesteros, R.; Chakhar, A.; del Pozo, S.; Gonzalez-Aquilera, D.; Moreno, A.M. Scalable pixel-based crop classification combining Sentinel-2 and Landsat-8 data time series: Case study of the Duero river basin. Agric. Syst. 2019, 171, 36-50. [CrossRef]

4. Waldner, F.; Canto, G.S.; Defourny, P. Automated annual cropland mapping using knowledge-based temporal features. ISPRS J. Photogramm. Remote Sens. 2015, 110, 1-13. [CrossRef]

5. Wang, S.; Azzari, G.; Lobell, D.B. Crop type mapping without field-level labels: Random forest transfer and unsupervised clustering techniques. Remote Sens. Environ. 2019, 222, 303-317. [CrossRef]

6. Elert, E. Rice by the numbers: A good grain. Nature 2014, 514, S50. [CrossRef] [PubMed]

7. Chapagain, A.K.; Hoekstra, A.Y. The green, blue and grey water footprint of rice from both a production and consumption perspective. Ecol. Econ. 2010, 70, 749-758. [CrossRef]

8. Yuan, W.; Liu, S.; Liu, W.; Zhao, S.; Dong, W.; Tao, F.; Chen, M.; Lin, H. Opportunistic market-driven regional shifts of cropping practices reduce food production capacity of China. Earth's Future 2018, 6, 634-642. [CrossRef]

9. Kritee, K.; Nair, D.; Zavala-Araiza, D.; Proville, J.; Rudek, J.; Adhya, T.; Loecke, T.; Esteves, T.; Balireddygari, S.; Dava, O.; et al. High nitrous oxide fluxes from rice indicate the need to manage water for both long-and short-term climate impacts. Proc. Natl. Acad. Sci. USA 2018, 115, 9720-9725. [CrossRef]

10. Netz, B.; Davidson, O.R.; Bosch, P.R.; Dave, R.; Meyer, L.A. Climate Change 2007: Mitigation. Contribution of Working Group III to the Fourth Assessment Report of the Intergovernmental Panel on Climate Change. Summary for Policymakers; Intergovernmental Panel on Climate Change (IPCC): Geneva, Switzerland, 2007.

11. Xiao, X.; Boles, S.; Liu, J.; Zhuang, D.; Frolking, S.; Li, C.; Salas, W.; Moore, B., III. Mapping paddy rice agriculture in southern China using multi-temporal MODIS images. Remote Sens. Environ. 2005, 95, 480-492. [CrossRef]

12. Xiao, X.; Boles, S.; Frolking, S.; Li, C.; Babu, J.Y.; Salas, W.; Moore, B., III. Mapping paddy rice agriculture in South and Southeast Asia using multi-temporal MODIS images. Remote Sens. Environ. 2006, 100, 95-113. [CrossRef]

13. Johnson, D.M.; Mueller, R. The 2009 cropland data layer. Photogramm. Eng. Remote Sens 2010, 76, 1201-1205.

14. Gumma, M.K.; Nelson, A.; Thenkabail, P.S.; Singh, A.N. Mapping rice areas of South Asia using MODIS multitemporal data. J. Appl. Remote Sens. 2011, 5, 053547. [CrossRef]

15. Bridhikitti, A.; Overcamp, T.J. Estimation of Southeast Asian rice paddy areas with different ecosystems from moderate-resolution satellite imagery. Agric. Ecosyst. Environ. 2012, 146, 113-120. [CrossRef]

16. Gumma, M.K.; Thenkabail, P.S.; Maunahan, A.; Islam, S.; Nelson, A. Mapping seasonal rice cropland extent and area in the high cropping intensity environment of Bangladesh using MODIS $500 \mathrm{~m}$ data for the year 2010. ISPRS J. Photogramm. Remote Sens. 2014, 91, 98-113. [CrossRef]

17. Dong, J.; Xiao, X.; Zhang, G.; Menarguez, M.A.; Choi, C.Y.; Qin, C.Y.; Luo, P.; Zhang, Y.; Moore, B. Northward expansion of paddy rice in northeastern Asia during 2000-2014. Geophys. Res. Lett. 2016, 43, 3754-3761. [CrossRef]

18. Dong, J.; Xiao, X.; Menarguez, M.A.; Zhang, G.; Qin, Y.; Thau, D.; Biradar, C.; Moore, B. Mapping paddy rice planting area in northeastern Asia with Landsat 8 images, phenology-based algorithm and Google Earth Engine. Remote Sens. Environ. 2016, 185, 142-154. [CrossRef] [PubMed] 
19. Singha, M.; Dong, J.; Zhang, G.; Xiao, X. High resolution paddy rice maps in cloud-prone Bangladesh and Northeast India using Sentinel-1 data. Sci. Data 2019, 6, 1-10. [CrossRef]

20. Ramadhani, F.; Pullanagari, R.; Kereszturi, G.; Procter, J. Automatic mapping of rice growth stages using the integration of SENTINEL-2, MOD13Q1, and SENTINEL-1. Remote Sens. 2020, 12, 3613. [CrossRef]

21. Yin, Q.; Liu, M.; Cheng, J.; Ke, Y.; Chen, X. Mapping paddy rice planting area in northeastern China using spatiotemporal data fusion and phenology-based method. Remote Sens. 2019, 11, 1699. [CrossRef]

22. Lasko, K.; Vadrevu, K.P.; Tran, V.T.; Justice, C. Mapping double and single crop paddy rice with Sentinel-1A at varying spatial scales and polarizations in Hanoi, Vietnam. IEEE J. Sel. Top. Appl. Earth Obs. Remote Sens. 2018, 11, 498-512. [CrossRef] [PubMed]

23. Chen, N.; Yu, L.; Zhang, X.; Shen, Y.; Zeng, L.; Hu, Q.; Niyogi, D. Mapping paddy rice fields by combining multi-temporal vegetation index and synthetic aperture radar remote sensing data using google earth engine machine learning platform. Remote Sens. 2020, 12, 2992. [CrossRef]

24. Manjunath, K.R.; More, R.S.; Jain, N.K.; Panigrahy, S.; Parihar, J.S. Mapping of rice-cropping pattern and cultural type using remote-sensing and ancillary data: A case study for South and Southeast Asian countries. Int. J. Remote Sens. 2015, 36, 6008-6030 [CrossRef]

25. Hoang, H.K.; Bernier, M.; Duchesne, S.; Tran, M.Y. Rice mapping using RADARSAT-2 dual-and quad-pol data in a complex land-use Watershed: Cau River Basin (Vietnam). IEEE J. Sel. Top. Appl. Earth Obs. Remote Sens. 2016, 9, 3082-3096. [CrossRef]

26. Wang, S.; Di Tommaso, S.; Faulkner, J.; Friedel, T.; Kennepohl, A.; Strey, R.; Lobell, D.B. Mapping crop types in southeast India with smartphone crowdsourcing and deep learning. Remote Sens. 2020, 12, 2957. [CrossRef]

27. Crisóstomo de Castro Filho, H.; Abílio de Carvalho Júnior, O.; Ferreira de Carvalho, O.L.; Pozzobon de Bem, P.; dos Santos de Moura, R.; Olino de Albuquerque, A.; Rosa Silva, C.; Guimarães Ferreira, P.H.; Fontes Guimarães, R.; Trancoso Gomes, R.A. Rice crop detection using LSTM, Bi-LSTM, and machine learning models from sentinel-1 time series. Remote Sens. 2020, $12,2655$. [CrossRef]

28. Zhao, H.; Chen, Z.; Jiang, H.; Jing, W.; Sun, L.; Feng, M. Evaluation of three deep learning models for early crop classification using sentinel-1A imagery time series-A case study in Zhanjiang, China. Remote Sens. 2019, 11, 2673. [CrossRef]

29. Thorp, K.R.; Drajat, D. Deep machine learning with Sentinel satellite data to map paddy rice production stages across West Java, Indonesia. Remote Sens. Environ. 2021, 265, 112679. [CrossRef]

30. Fiorillo, E.; Di Giuseppe, E.; Fontanelli, G.; Maselli, F. Lowland rice mapping in Sédhiou Region (Senegal) using sentinel 1 and sentinel 2 data and random forest. Remote Sens. 2020, 12, 3403. [CrossRef]

31. Dong, J.; Fu, Y.; Wang, J.; Tian, H.; Fu, S.; Niu, Z.; Han, W.; Zheng, Y.; Huang, J.; Yiam, W. Early-season mapping of winter wheat in China based on Landsat and Sentinel images. Earth Syst. Sci. Data 2020, 12, 3081-3095. [CrossRef]

32. Yang, L.; Huang, R.; Huang, J.; Lin, T.; Wang, L.; Mijiti, R.; Wei, P.; Tang, C.; Shao, J.; Li, Q.; et al. Semantic Segmentation Based on Temporal Features: Learning of Temporal-Spatial Information from Time-Series SAR Images for Paddy Rice Mapping. IEEE Trans. Geosci. Remote Sens. 2021, 1-16. [CrossRef]

33. Liu, W.; Dong, J.; Xiang, K.; Wang, S.; Han, W.; Yuan, W. A sub-pixel method for estimating planting fraction of paddy rice in Northeast China. Remote Sens. Environ. 2018, 205, 305-314. [CrossRef]

34. Jeong, S.; Ko, J.; Yeom, J.M. Nationwide projection of rice yield using a crop model integrated with geostationary satellite imagery: A case study in South Korea. Remote Sens. 2018, 10, 1665. [CrossRef]

35. Zhou, Y.; Xiao, X.; Qin, Y.; Dong, J.; Zhang, G.; Kou, W.; Jin, C.; Whang, J.; Li, X. Mapping paddy rice planting area in rice-wetland coexistent areas through analysis of Landsat 8 OLI and MODIS images. Int. J. Appl. Earth Obs. Geoinf. 2016, 46, 1-12. [CrossRef] [PubMed]

36. Dong, J.; Xiao, X.; Kou, W.; Qin, Y.; Zhang, G.; Li, L.; Jin, C.; Zhou, Y.; Wanh, J.; Biradar, C.; et al. Tracking the dynamics of paddy rice planting area in 1986-2010 through time series Landsat images and phenology-based algorithms. Remote Sens. Environ. 2015, 160, 99-113. [CrossRef]

37. Son, N.T.; Chen, C.F.; Chen, C.R.; Guo, H.Y. Classification of multitemporal Sentinel-2 data for field-level monitoring of rice cropping practices in Taiwan. Adv. Space Res. 2020, 65, 1910-1921. [CrossRef]

38. Shao, Y.; Fan, X.; Liu, H.; Xiao, J.; Ross, S.; Brisco, B.; Brown, B.; Staples, G. Rice monitoring and production estimation using multitemporal RADARSAT. Remote Sens. Environ. 2001, 76, 310-325. [CrossRef]

39. Bouvet, A.; Le Toan, T. Use of ENVISAT/ASAR wide-swath data for timely rice fields mapping in the Mekong River Delta. Remote Sens. Environ. 2011, 115, 1090-1101. [CrossRef]

40. Phan, H.; Le Toan, T.; Bouvet, A.; Nguyen, L.D.; Pham Duy, T.; Zribi, M. Mapping of rice varieties and sowing date using X-band SAR data. Sensors 2018, 18, 316. [CrossRef]

41. Chul Jung, H.; Alsdorf, D. Repeat-pass multi-temporal interferometric SAR coherence variations with Amazon floodplain and lake habitats. Int. J. Remote Sens. 2010, 31, 881-901. [CrossRef]

42. Schlaffer, S.; Matgen, P.; Hollaus, M.; Wagner, W. Flood detection from multi-temporal SAR data using harmonic analysis and change detection. Int. J. Appl. Earth Obs. Geoinf. 2015, 38, 15-24. [CrossRef]

43. Guo, Y.; Jia, X.; Paull, D.; Benediktsson, J.A. Nomination-favoured opinion pool for optical-SAR-synergistic rice mapping in face of weakened flooding signals. ISPRS J. Photogramm. Remote Sens. 2019, 155, 187-205. [CrossRef]

44. Mansaray, L.R.; Huang, W.; Zhang, D.; Huang, J.; Li, J. Mapping rice fields in urban Shanghai, southeast China, using Sentinel-1A and Landsat 8 datasets. Remote Sens. 2017, 9, 257. [CrossRef] 
45. Bazzi, H.; Baghdadi, N.; El Hajj, M.; Zribi, M.; Minh, D.H.T.; Ndikumana, E.; Courault, D.; Belhouchette, H. Mapping paddy rice using Sentinel-1 SAR time series in Camargue, France. Remote Sens. 2019, 11, 887. [CrossRef]

46. Zhang, X.; Wu, B.; Ponce-Campos, G.E.; Zhang, M.; Chang, S.; Tian, F. Mapping up-to-date paddy rice extent at $10 \mathrm{~m}$ resolution in china through the integration of optical and synthetic aperture radar images. Remote Sens. 2018, 10, 1200. [CrossRef]

47. Zhan, P.; Zhu, W.; Li, N. An automated rice mapping method based on flooding signals in synthetic aperture radar time series. Remote Sens. Environ. 2021, 252, 112112. [CrossRef]

48. Sakoe, H.; Chiba, S. Dynamic programming algorithm optimization for spoken word recognition. IEEE Trans. Acoust. Speech Signal Process. 1978, 26, 43-49. [CrossRef]

49. Petitjean, F.; Inglada, J.; Gançarski, P. Satellite image time series analysis under time warping. IEEE Trans. Geosci. Remote Sens. 2012, 50, 3081-3095. [CrossRef]

50. Maus, V.; Câmara, G.; Cartaxo, R.; Sanchez, A.; Ramos, F.M.; De Queiroz, G.R. A time-weighted dynamic time warping method for land-use and land-cover mapping. IEEE J. Sel. Top. Appl. Earth Obs. Remote Sens. 2016, 9, 3729-3739. [CrossRef]

51. Chen, B.; Xu, B.; Zhu, Z.; Yuan, C.; Suen, H.P.; Guo, J.; Xu, N.; Li, W.; Zhao, Y.; Yu, C.; et al. Stable classification with limited sample: Transferring a 30-m resolution sample set collected in 2015 to mapping 10-m resolution global land cover in 2017. Sci. Bull. 2019, 64, 370-373.

52. Chang, K.W.; Shen, Y.; Lo, J.C. Predicting rice yield using canopy reflectance measured at booting stage. Agron. J. 2005, 97, 872-878. [CrossRef]

53. Brouwer, C.; Prins, K.; Heibloem, M. Irrigation Water Management: Irrigation Scheduling; Training Manual; FAO: Rome, Italy, 1989.

54. Dong, J.; Xiao, X. Evolution of regional to global paddy rice mapping methods: A review. ISPRS J. Photogramm. Remote Sens. 2016, 119, 214-227. [CrossRef]

55. Zhao, R.; Li, Y.; Ma, M. Mapping paddy rice with satellite remote sensing: A review. Sustainability 2021, 13, 503. [CrossRef]

56. Kurosu, T.; Fujita, M.; Chiba, K. Monitoring of rice crop growth from space using the ERS-1 C-band SAR. IEEE Trans. Geosci. Remote Sens. 1995, 33, 1092-1096. [CrossRef]

57. Choudhury, I.; Chakraborty, M. SAR signature investigation of rice crop using RADARSAT data. Int. J. Remote Sens. 2006, 27, 519-534. [CrossRef]

58. Belgiu, M.; Csillik, O. Sentinel-2 cropland mapping using pixel-based and object-based time-weighted dynamic time warping analysis. Remote Sens. Environ. 2018, 204, 509-523. [CrossRef]

59. Steele-Dunne, S.C.; McNairn, H.; Monsivais-Huertero, A.; Judge, J.; Liu, P.W.; Papathanassiou, K. Radar remote sensing of agricultural canopies: A review. IEEE J. Sel. Top. Appl. Earth Obs. Remote Sens. 2017, 10, 2249-2273. [CrossRef]

60. Le Toan, T.; Ribbes, F.; Wang, L.F.; Floury, N.; Kung-Hau, D.; Kong, J.A.; Fujita, M.; Kurosu, T. Rice crop mapping and monitoring using ERS-1 data based on experiment and modeling results. IEEE Trans. Geosci. Remote Sens. 1997, 35, 41-56. [CrossRef]

61. Lopez-Sanchez, J.M.; David Ballester-Berman, J.; Hajnsek, I. First results of rice monitoring practices in Spain by means of time series of TerraSAR-X dual-pol images. IEEE J. Sel. Top. Appl. Earth Obs. Remote Sens. 2010, 4, 412-422. [CrossRef]

62. Gebhardt, S.; Huth, J.; Nguyen, L.D.; Roth, A.; Kunzer, C. A comparison of TerraSAR-X Quadpol backscattering with RapidEye multispectral vegetation indices over rice fields in the Mekong Delta, Vietnam. Int. J. Remote Sens. 2012, 33, 7644-7661. [CrossRef]

63. Koppe, W.; Gnyp, M.L.; Hütt, C.; Yinkun, Y.; Yuxin, M.; Xinping, C.; Georg, B. Rice monitoring with multi-temporal and dual-polarimetric TerraSAR-X data. Int. J. Appl. Earth Obs. Geoinf. 2013, 21, 568-576. [CrossRef] 